\title{
Baseline Survey of the Neuroradiology Work Environment in the United States with Reported Trends in Clinical Work, Nonclinical Work, Perceptions of Trainees, and Burnout Metrics
}

\author{
(1)J.Y. Chen and (1DF.J. Lexa
}

\begin{abstract}
BACKGROUND AND PURPOSE: Neuroradiologists have faced continuously increasing clinical workloads. Our aim was to establish and report a baseline survey of the current neuroradiology work environment in the United States and of experiential changes in recent years.

MATERIALS AND METHODS: A voluntary survey was sent to practicing and out-of-training members of the American Society of Neuroradiology in the United States. Selected measures included workday volume and length, burnout symptoms, participation in academic and practice-building duties; effects on perceived interpretation quality, communication of abnormal results, and consideration of early retirement or career changes, among others.
\end{abstract}

RESULTS: Four hundred thirty-two respondents across a broad range of experience reported the following: 52.8\% (224/424) with teaching responsibilities; 93\% (399/430) with workdays extending at least 1 hour past expected, in 45\% (193/430) frequently or always; $71.9 \%$ (309/430) reading more cases per hour compared to previous years; $79.5 \%$ (341/429) sometimes-to-always interpreting cases faster than comfortable for optimal interpretation; and $67.8 \%(292 / 431)$ sometimes or more often with inadequate time to discuss abnormal results. Burnout symptoms ranged between $49 \%$ and $75 \%$ (211/428 to 322/428) across 4 indices. For academic activities of teaching, mentoring, and research/publications, a mean of $94.3 \%$ reported cut-backs during the past few years. For practice-building activities, $92 \%$ reported cut-backs, 51.6\% (222/429) considered early retirement, and 38.8\% (167/429) considered changing careers.

CONCLUSIONS: Increasing clinical demands have coincided with destructive effects in the work environment and the ability and desire of neuroradiologists in the United States to perform academic or practice-building duties with a substantial incidence of burnout symptoms. While this survey does not prove causation, the trends and the correlations should be concerning to the leaders of radiology and warrant further monitoring.

ABBREVIATIONS: ASNR = American Society of Neuroradiology; $\mathrm{RVU}=$ relative value unit

$\mathrm{n}$ $\mathrm{n}$ the United States, the work volume of neuroradiologists has mirrored that of radiology and health care in general, with increases in annual work productivity (number of Relative Value Units [RVUs]) during the past decade. ${ }^{1}$ This is part of a longer term trend in increased workloads that occurred in the prior de-

Received December 12, 2016; accepted after revision March 3, 2017.

From the Department of Radiology (J.Y.C.), San Diego Veterans Administration Health System, San Diego, California; Department of Radiology (J.Y.C.), Division of Neuroradiology, University of California San Diego Health System, San Diego, California; The Global Consulting Practicum and Department of Marketing (F.J.L.), The Wharton School, University of Pennsylvania, Philadelphia, Pennsylvania; and Radiology Leadership Institute of the American College of Radiology (F.J.L.), Reston, Virginia. Paper previously presented, in part, at: American College of Radiology-Radiology Business Management Association Forum, January 13-15, 2017; Orlando, Florida. Please address correspondence to James Y. Chen, MD, 3350 La Jolla Village Dr, MC 114, La Jolla, CA 92161; e-mail: jamesychen@ucsd.edu

三 Indicates article with supplemental on-line appendix and tables.

http://dx.doi.org/10.3174/ajnr.A5215 cade. ${ }^{2}$ The rise in productivity demand has resulted in some practices requiring the use of specific work-output RVU targets as thresholds for compensation or hiring without adequate regard for their effects on workers or potential limits to human task performance. Neuroradiologists' target and total RVUs are the highest of radiology subspecialties, ${ }^{3-5}$ and neuroradiologists may serve as a bellwether for the broader radiologist population. To date, there has not been a single national survey collecting data on the neuroradiologists' practice work environment evaluating compensation, workplace hiring practices, effects on productivity, and output as well as burnout, to our knowledge.

The emphasis on ever-increasing RVU targets may have downstream effects on radiology, such as increased speed of interpretation, decreased remaining time for training residents and fellows, decreased research output, decreased time for practice building (such as quality projects, administrative committees), and potential burnout of radiologists. Worker burnout is a 
known contributor to workplace errors and is costly in terms of personal and institutional impact. Burnout of radiologists and other physicians is becoming an important topic, not just in the United States, but also in other countries. ${ }^{6-8}$

This survey of neuroradiologists was performed to establish a national baseline for work patterns in the United States to allow tracking and comparison with future surveys. The survey will be repeated and updated biennially to allow tracking and comparisons as the work environment in the United States continues to change. This schedule will provide better data to practitioners and practice managers for understanding, measuring, and (perhaps) modifying the work environment.

\section{MATERIALS AND METHODS}

A voluntary on-line survey was sent to practicing neuroradiologists in the United States who are members of the American Society of Neuroradiology (ASNR). It was inclusive of the neuroradiologists in the United States and excludes neuroradiologist members who were outside the United States. The survey was launched at the beginning of August 2016 and was open until October 5, 2016. The current membership includes practicing physicians and fellows in training. We excluded the latter because many of the questions interrogated trends and changes with a baseline that was longer than the training period. Although participation was voluntary, an incentive was offered in the form of a drawing for a gift certificate valued at $\$ 250$, given the length of the survey.

The survey (On-line Appendix) was collected electronically by using Survey Monkey (http://www.surveymonkey.com), a survey Web site that allows viewing of survey responses only by the owner of the survey. The American Society of Neuroradiology agreed to send the survey out to members in the United States by e-mail. Members who chose to participate did so by clicking the e-mail link to open the Survey Monkey Web page containing the survey and completed it on their device. No direct contact occurred between the study Principal Investigator or the survey respondents except for announcement to the respondents of the winner of the prize associated with the lottery.

The e-mail addresses and surveys were initially linked temporarily only if the participant chose to participate in the prize lottery. The e-mail address was collected only for the lottery and then was separated from the survey response. The survey responses were then de-linked from any e-mail address in the investigator's response data base. Until the e-mail addresses were separated from the responses, they were considered confidential. Once the responses were separated from the e-mail addresses, there was no mechanism for tracking responses back to a specific e-mail address.

Survey data were then checked for quality and to remove duplicates. Internet Protocol addresses, survey submission time, and e-mails were cross-referenced to identify responses that could be considered duplicates.

In 1 case, duplicate answers from the same ASNR member were reconciled before inclusion in the analysis. Initial data display was performed by using the on-line survey tool output; then, more advanced data analysis was performed by importing the data into an Excel (Microsoft, Redmond, Washington) spreadsheet. Statistical comparison of selected yes/no results between groups was performed by using n-1 comparison.

Results were broken into several groups for analysis: overall results, respondents who routinely teach trainees versus respondents who do not routinely teach trainees, and roughly by demographic generation with practice experience as a proxy. If one assumed contiguous education and training with completion of the fellowship at 32 years of age, dividing respondents at and below 20 years of experience would roughly divide respondents into 2 major demographic generations. This division would approximately divide respondents at a date of birth of 1964 , roughly "Generation X" including 1 or 2 years of "Millennials" versus "Baby Boomers" and "Greatest Generation" with $>20$ years of experience.

\section{RESULTS}

Article length constraints limit text reporting of the results to the overall results and selected subgroups. The results tables (Tables 1-3 and On-line Tables 1-3) provide more detailed comparisons of subgroups, including teaching versus nonteaching, and $<20$ years of experience versus $>20$ years of experience.

Only 1 duplicate response from 1 Internet Protocol address was discovered. Once the duplicated responses were reconciled and the 20 member-in-training responses were excluded, a total of 432 participants were included for further analysis. There was minimal survey fatigue; although questions could be skipped, 99.3\% (429/432) of the respondents answered the last question. The results below are based on the percentage of participants who responded to a question.

\section{Demographic Results}

A slight majority of respondents, $52.8 \%$ versus $47.2 \%$, reported that they routinely teach radiology residents or fellows, giving the survey a relatively well-balanced sample of both training settings and nontraining sites of neuroradiology work.

The dataset was also fairly well-distributed by experience from the first 5 years out of training to those with $>31$ years of posttraining work experience (Fig 1).

The survey group encompassed a fairly wide spread of respondents with regard to the anticipated number of years remaining in their careers. Fourteen percent of the respondents were within $\leq 5$ years of planned retirement, with a peak of $20 \%$ planning to work $11-15$ years and $19.5 \%$ planning to work $\geq 26$ years. There was less diversity with regard to the number of jobs held: Three of 4 of the respondents $(77.8 \%)$ had not changed employers in past few years, while 17.4 had changed employers once, 3.9\% had changed twice, and $<1 \%$ had changed $\geq 3$ times.

\section{Reported Compensation and Time Off}

Slightly less than half, $48.5 \%$, reported that their compensation versus the prior year was unchanged; $28.4 \%$ reported an increase; and $23.1 \%$ reported a decrease. Time off the clinical schedule (vacation and nonclinical professional time) was more stable, with $73 \%$ reporting no change since the prior year, but with a more concerning trend in that those reporting a decrease (18.7\%) outnumbered those with an increase (8.4\%). Similarly, if we looked at weeks rather than days, $70.8 \%$ reported no change, but 
Table 1: Respondent demographics

\begin{tabular}{|c|c|c|c|c|c|c|c|c|c|c|c|c|c|c|c|}
\hline & \multicolumn{3}{|c|}{ Overall } & \multicolumn{3}{|c|}{ Teaching } & \multicolumn{3}{|c|}{ Nonteaching } & \multicolumn{3}{|c|}{$\begin{array}{l}<20 \text { Years' } \\
\text { Experience }\end{array}$} & \multicolumn{3}{|c|}{$\begin{array}{l}\geq 20 \text { Years' } \\
\text { Experience }\end{array}$} \\
\hline & $\%$ & No. & Skipped & $\%$ & No. & Skipped & $\%$ & No. & Skipped & $\%$ & No. & Skipped & $\%$ & No. & Skipped \\
\hline 1) Do you teach radiology trainees? & & & 8 & & & 0 & & & 0 & & & 3 & & & 5 \\
\hline Yes & $52.8 \%$ & 224 & & $100.0 \%$ & 224 & & $0.0 \%$ & 0 & & $54.4 \%$ & 141 & & $50.3 \%$ & 83 & \\
\hline No & $47.2 \%$ & 200 & & $0.0 \%$ & 0 & & $100.0 \%$ & 208 & & $45.6 \%$ & 118 & & $49.7 \%$ & 82 & \\
\hline 2) How long have you been in practice? & & & 0 & & & 0 & & & 0 & & & 0 & & & 0 \\
\hline Still in training & $0.0 \%$ & 0 & & $0.0 \%$ & 0 & & $0.0 \%$ & 0 & & $0.0 \%$ & 0 & & $0.0 \%$ & 0 & \\
\hline $1-5 \mathrm{yr}$ beyond training & $16.2 \%$ & 70 & & $17.0 \%$ & 38 & & $15.5 \%$ & 31 & & $26.7 \%$ & 70 & & $0.0 \%$ & 0 & \\
\hline $6-10$ yr beyond training & $19.4 \%$ & 84 & & $24.1 \%$ & 54 & & $15.0 \%$ & 30 & & $32.1 \%$ & 84 & & $0.0 \%$ & 0 & \\
\hline 11-15 yr beyond training & $13.2 \%$ & 57 & & $12.5 \%$ & 28 & & $14.0 \%$ & 28 & & $21.8 \%$ & 57 & & $0.0 \%$ & 0 & \\
\hline $16-20$ yr beyond training & $11.8 \%$ & 51 & & $9.4 \%$ & 21 & & $14.5 \%$ & 29 & & $19.5 \%$ & 51 & & $0.0 \%$ & 0 & \\
\hline $21-25 \mathrm{yr}$ beyond training & $16.7 \%$ & 72 & & $12.9 \%$ & 29 & & $20.5 \%$ & 41 & & $0.0 \%$ & 0 & & $42.4 \%$ & 72 & \\
\hline $26-30 \mathrm{yr}$ beyond training & $13.0 \%$ & 56 & & $12.9 \%$ & 29 & & $12.5 \%$ & 25 & & $0.0 \%$ & 0 & & $32.9 \%$ & 56 & \\
\hline$\geq 31$ yr beyond training & $9.7 \%$ & 42 & & $11.2 \%$ & 25 & & $8.0 \%$ & 16 & & $0.0 \%$ & 0 & & $24.7 \%$ & 42 & \\
\hline $\begin{array}{l}\text { 3) When do you intend to retire from } \\
\text { radiology practice? }\end{array}$ & & & 2 & & & 1 & & & 1 & & & 0 & & & 2 \\
\hline $0-5 \mathrm{yr}$ & $14.0 \%$ & 60 & & $10.8 \%$ & 24 & & $17.1 \%$ & 34 & & $1.5 \%$ & 4 & & $33.3 \%$ & 56 & \\
\hline $6-10 \mathrm{yr}$ & $17.4 \%$ & 75 & & $15.7 \%$ & 35 & & $19.1 \%$ & 38 & & $9.5 \%$ & 25 & & $29.8 \%$ & 50 & \\
\hline $11-15 \mathrm{yr}$ & $20.7 \%$ & 89 & & $17.9 \%$ & 40 & & $24.1 \%$ & 48 & & $17.9 \%$ & 47 & & $25.0 \%$ & 42 & \\
\hline $16-20 \mathrm{yr}$ & $14.7 \%$ & 63 & & $13.5 \%$ & 30 & & $16.6 \%$ & 33 & & $21.4 \%$ & 56 & & $4.2 \%$ & 7 & \\
\hline $21-25 \mathrm{yr}$ & $13.7 \%$ & 59 & & $16.6 \%$ & 37 & & $11.1 \%$ & 22 & & $22.1 \%$ & 58 & & $0.6 \%$ & 1 & \\
\hline $26-30 \mathrm{yr}$ & $11.6 \%$ & 50 & & $13.5 \%$ & 30 & & $9.5 \%$ & 19 & & $17.9 \%$ & 47 & & $1.8 \%$ & 3 & \\
\hline$\geq 31 \mathrm{yr}$ & $7.9 \%$ & 34 & & $12.1 \%$ & 27 & & $2.5 \%$ & 5 & & $9.5 \%$ & 25 & & $5.4 \%$ & 9 & \\
\hline
\end{tabular}

Table 2: Burnout measures

\begin{tabular}{|c|c|c|c|c|c|c|c|c|c|c|c|c|c|c|c|}
\hline & \multicolumn{3}{|c|}{ Overall } & \multicolumn{3}{|c|}{ Teaching } & \multicolumn{3}{|c|}{ Nonteaching } & \multicolumn{3}{|c|}{ <20 Years' Experience } & \multicolumn{3}{|c|}{$\geq 20$ Years' Experience } \\
\hline & $\%$ & No. & Skipped & $\%$ & No. & Skipped & $\%$ & No. & Skipped & $\%$ & No. & Skipped & $\%$ & No. & Skippec \\
\hline \multicolumn{16}{|l|}{$\begin{array}{l}\text { 27) Compared with } 5 \text { years ago, have you } \\
\text { experienced }\end{array}$} \\
\hline Greater fatigue? & & & 4 & & & 2 & & & 2 & & & 4 & & & 0 \\
\hline Yes & $75.2 \%$ & 322 & & $77.9 \%$ & 173 & & $71.2 \%$ & 141 & & $76.4 \%$ & 197 & & $73.5 \%$ & 125 & \\
\hline No & $24.8 \%$ & 106 & & $22.1 \%$ & 49 & & $28.8 \%$ & 57 & & $23.6 \%$ & 61 & & $26.5 \%$ & 45 & \\
\hline Difficulty relaxing after work? & & & 4 & & & 2 & & & 2 & & & 4 & & & 0 \\
\hline Yes & $59.3 \%$ & 254 & & $62.2 \%$ & 138 & & $55.1 \%$ & 109 & & $65.1 \%$ & 168 & & $50.6 \%$ & 86 & \\
\hline No & $40.7 \%$ & 174 & & $37.8 \%$ & 84 & & $44.9 \%$ & 89 & & $34.9 \%$ & 90 & & $49.4 \%$ & 84 & \\
\hline Greater anxiety or depression? & & & 4 & & & 2 & & & 2 & & & 4 & & & 0 \\
\hline Yes & $49.3 \%$ & 211 & & $49.5 \%$ & 110 & & $49.0 \%$ & 97 & & $52.7 \%$ & 136 & & $44.1 \%$ & 75 & \\
\hline No & $50.7 \%$ & 217 & & $50.5 \%$ & 112 & & $51.0 \%$ & 101 & & $47.3 \%$ & 122 & & $55.9 \%$ & 95 & \\
\hline $\begin{array}{l}\text { Diminished sense of enthusiasm or } \\
\text { effectiveness at work? }\end{array}$ & & & 5 & & & 3 & & & 2 & & & 5 & & & 0 \\
\hline Yes & $68.1 \%$ & 291 & & $72.9 \%$ & 161 & & $63.1 \%$ & 125 & & $69.6 \%$ & 179 & & $65.9 \%$ & 112 & \\
\hline No & $31.9 \%$ & 136 & & $27.1 \%$ & 60 & & $36.9 \%$ & 73 & & $30.4 \%$ & 78 & & $34.1 \%$ & 58 & \\
\hline
\end{tabular}

Table 3: Administrative adjustments to workplace and thoughts of personal changes in career and retirement

\begin{tabular}{|c|c|c|c|c|c|c|c|c|c|c|c|c|c|c|c|}
\hline & \multicolumn{3}{|c|}{ Overall } & \multicolumn{3}{|c|}{ Teaching } & \multicolumn{3}{|c|}{ Nonteaching } & \multicolumn{3}{|c|}{$<20$ Years' Experience } & \multicolumn{3}{|c|}{$\geq 20$ Years' Experience } \\
\hline & $\%$ & No. & Skipped & $\%$ & No. & Skipped & $\%$ & No. & Skipped & $\%$ & No. & Skipped & $\%$ & No. & Skipped \\
\hline $\begin{array}{l}\text { 28) Over the last few years, have your } \\
\text { practice administrators made } \\
\text { concrete changes to the } \\
\text { practice to balance changes of } \\
\text { your clinical workload with your } \\
\text { nonclinical duties? }\end{array}$ & & & 2 & & & 1 & & & 1 & & & 1 & & & 1 \\
\hline Yes & $14.2 \%$ & 61 & & $15.7 \%$ & 35 & & $12.6 \%$ & 25 & & $13.8 \%$ & 36 & & $14.8 \%$ & 25 & \\
\hline No & $66.5 \%$ & 286 & & $74.4 \%$ & 166 & & $58.3 \%$ & 116 & & $69.0 \%$ & 180 & & $62.7 \%$ & 106 & \\
\hline NA & $19.3 \%$ & 83 & & $9.9 \%$ & 22 & & $29.1 \%$ & 58 & & $17.2 \%$ & 45 & & $22.5 \%$ & 38 & \\
\hline $\begin{array}{l}\text { 29) Have you considered retiring } \\
\text { earlier than you had initially } \\
\text { intended when first starting } \\
\text { practice? }\end{array}$ & & & 3 & & & 0 & & & 3 & & & 3 & & & 0 \\
\hline Yes & $51.7 \%$ & 222 & & $51.3 \%$ & 115 & & $51.8 \%$ & 102 & & $57.9 \%$ & 150 & & $42.4 \%$ & 72 & \\
\hline No & $48.3 \%$ & 207 & & $48.7 \%$ & 109 & & $48.2 \%$ & 95 & & $42.1 \%$ & 109 & & $57.6 \%$ & 98 & \\
\hline $\begin{array}{l}\text { 30) In the last few years, have you } \\
\text { considered changing careers? }\end{array}$ & & & 3 & & & 2 & & & 1 & & & 1 & & & 2 \\
\hline Yes & $38.9 \%$ & 167 & & $40.5 \%$ & 90 & & $37.7 \%$ & 75 & & $46.0 \%$ & 120 & & $28.0 \%$ & 47 & \\
\hline No & $61.1 \%$ & 262 & & $59.5 \%$ & 132 & & $62.3 \%$ & 124 & & $54.0 \%$ & 141 & & $72.0 \%$ & 121 & \\
\hline
\end{tabular}

those reporting working more weeks (23.2\%) outnumbered those reporting working fewer $(6.0 \%)$.

\section{Perceptions of Clinical Workload and Time at Work}

Close to one-third (32.5\%) of respondents said that radiology compensation was determined by RVU targets. At a personal level, most
(62.7\%) reported that during the past few years, their RVU production had increased, while $6.5 \%$ reported a decrease, $16.4 \%$ reported that it was the same, and $14.4 \%$ did not know. Reporting on the trend of the number of hours worked per day during the past few years, almost half (49.7\%) reported working longer days, while a slightly smaller number, $46.9 \%$, reported that they worked about the same, 


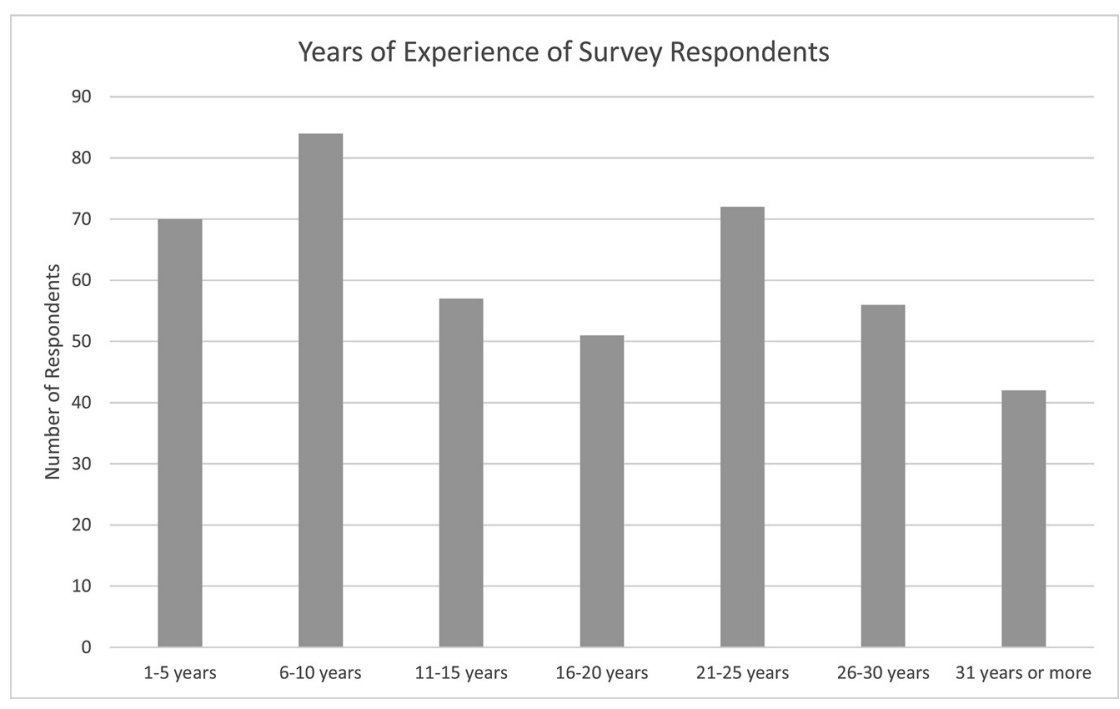

FIG 1. Five-year periods of practice experience of survey respondents.

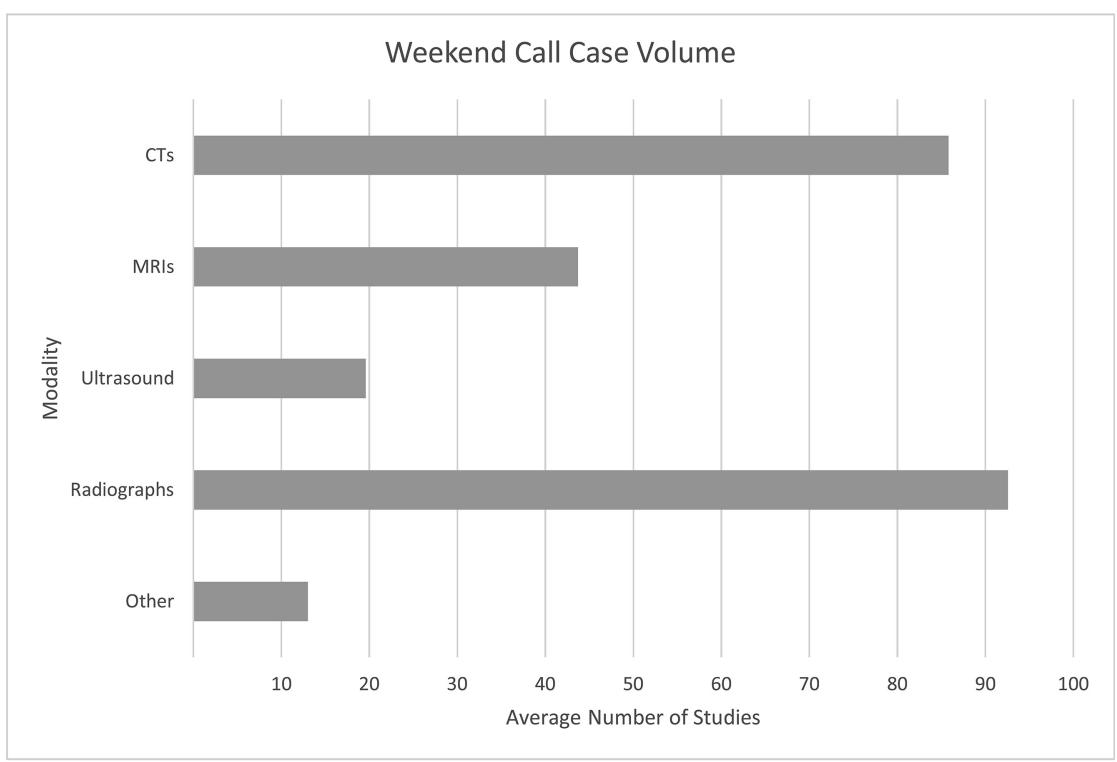

FIG 2. Number of studies by technique interpreted during a weekend between Friday evening and Monday morning. This is a gross overstatement of individual workload, as these numbers do not account for case number and modality differences between fully subspecialized and partly subspecialized call responsibilities.

and only $3.5 \%$ reported a shorter workday. In a related question, the participants were asked how often they had to stay $\geq 1$ hour beyond the expected workday. Here only slightly more than one-quarter reported that a longer stay never or rarely occurred $(27.4 \%$, sum of 2 responses). More than half the respondents reported that it happened sometimes or frequently (57.2\%, sum of 2 responses), and most interesting were the $15.4 \%$ who said they always stayed an hour or more past the end of the "expected workday."

With the regard to the number of workdays in the year, more than half $(54.1 \%)$ reported that this was stable during the past few years. Of the remainder, $38.0 \%$ reported working more days and $7.9 \%$ reported working fewer.

With regard to the trends in the intensity of work, $24 \%$ reported reading the same number of cases per hour, while only $4.2 \%$ reported reading fewer, and most, $71.9 \%$, were reading more per hour. When asked how often a participant thought that they were reading faster than they were comfortable with, only around one-fifth $(20.5 \%)$ reported that reading faster was rare or never occurred. Almost half $(44.1 \%)$ reported that this occurred sometimes; $29.1 \%$ said that this was frequent; and $6.3 \%$ of the participants said that this occurred "always." When it came to reports, a similar distribution occurred with $8.1 \%$ reporting that they always signed reports faster than they were "comfortable for optimal communication and clarity." When asked if they had too little time to discuss important abnormal results with clinicians, about one-third (32.3\%) responded that the lack of time rarely or never happened, while $35.3 \%$ said that it occurred sometimes, $27.4 \%$ stated it was frequent, and for $5.1 \%$ this always happened. In reporting abnormal results, there was a similar distribution, with $4.7 \%$ of respondents stating that they always had too little time to report abnormal results.

When asked about reading cases when sleep-deprived, approximately half $(48.72 \%)$ said this was a rare or never occurrence, while $36.0 \%$ reported doing this sometimes, $13.5 \%$ did it frequently, and $1.9 \%$ did it "always."

\section{On-Call Responsibilities and Perceptions}

For the number of duty day/nights of call coverage, $54.1 \%$ of respondents reported no change, while in the remainder, those reporting an increase, 36.6\%, outnumbered those reporting a decrease, $9.3 \%$. Regarding the perception of on-call duty, only a little more than one-third (35.5\%) reported that the difficulty of on call was stable, while of the remainder, those reporting greater difficulty, $59.7 \%$, outnumbered those who thought their on-call duty was easier, $4.9 \%$.

Participants were asked to provide information about what they read on weekend call, defined as Friday evening to Monday morning. The following averages were obtained from 328 respondents: $86 \mathrm{CTs}$, 44 MRIs, 20 ultrasounds, 93 radiographs, and 13 other (Fig 2), which likely grossly overestimates studies interpreted due to limitations of context in the survey instrument. Important contextual information not obtained as part of the survey included the number of hours on-call, whether calls were fully subspecialized, and whether final or preliminary interpretation was provided, among others.

Of respondents, $62.2 \%$ thought that the number of poorly indicated or unindicated studies had increased, while only $4.0 \%$ thought that they had decreased, with $33.8 \%$ reporting a stable amount. 


\section{Trends in Perceptions of Trainees}

Of those who train neuroradiology fellows, most thought that the ability of the trainees was the same as in the past, but of those

\section{Perception of Neuroradiology Fellow Capability over the Last Few Years}

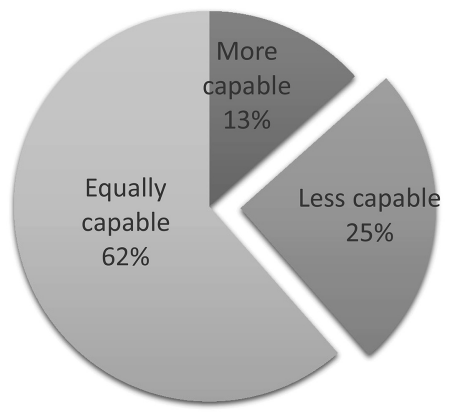

FIG 3. Faculty reported change in the capabilities of fellowsin-training.

\section{Perception of Resident Capability Over the Last Few Years}

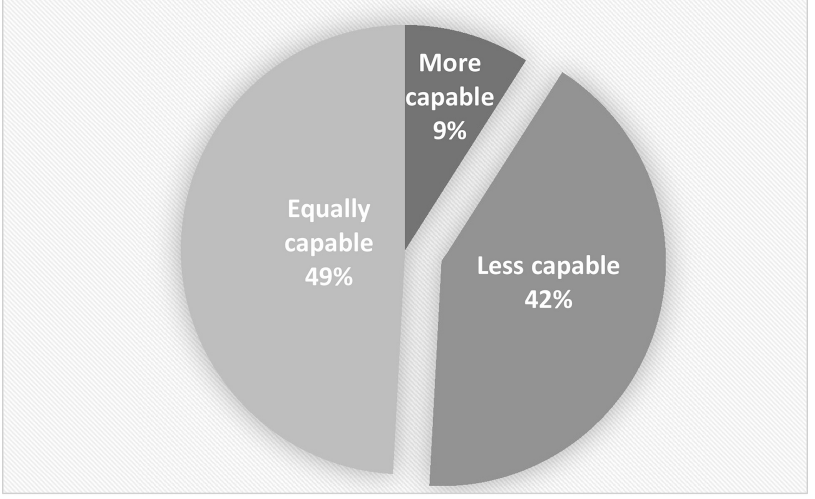

FIG 4. Faculty reported change in the capabilities of residentsin-training.

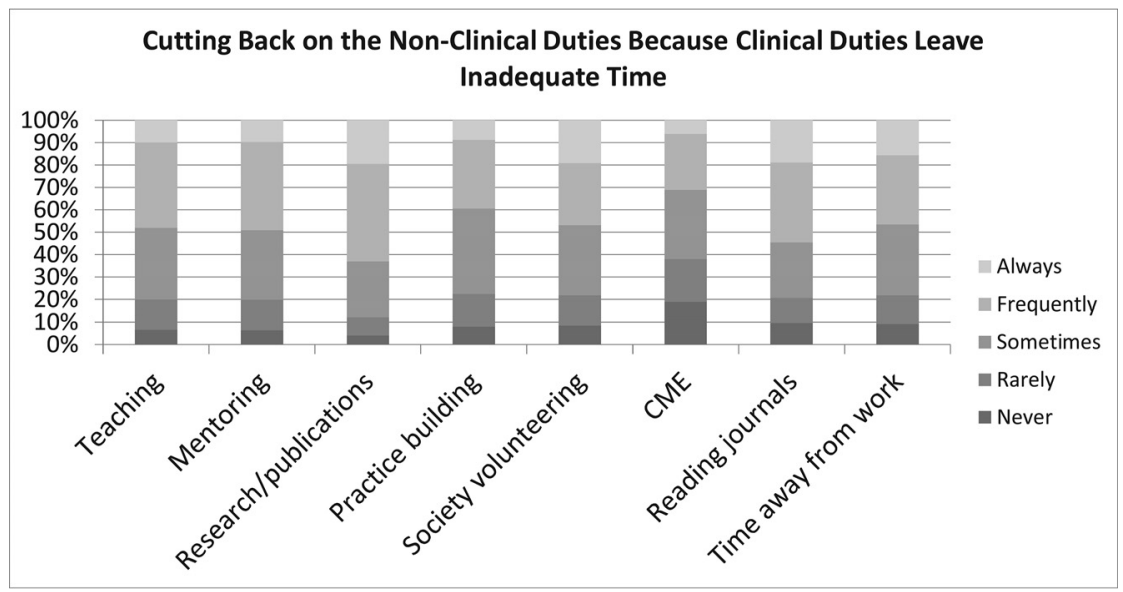

FIG 5. The percentage of respondents reporting cutting back time spent performing various nonclinical duties who consider those duties part of their job description. This specifically excludes respondents who answered, "Not Applicable" to those duties. reporting a change, almost twice as many thought that abilities had declined (Fig 3).

Of respondents who train residents, of those who noticed a change in the past few years, $>4$ times as many respondents found a reduction in resident ability than an increase (Fig 4).

\section{Changes in Nonclinical Activities Occurring in Parallel with Increased Clinical Work}

Most respondents reported cutting back on $\geq 1$ key nonclinical professional activity (Fig 5 and On-line Table 3 ) in the past few years. This included key elements of the "academic triad," including teaching and research, as well as mentoring, volunteer work for professional societies, practice building, and personal medical education. Concordant with the earlier results, most of the respondents also reported an impact on the amount of time they have away from work.

Excluding respondents for whom these activities are "Not Applicable," only a small minority of respondents (2 categories combined) never or rarely needed to cut back on the following activities, whereas most (3 categories combined) reported sometimes, frequently, or always cutting back (Fig 5). Regarding cutting back on teaching, of the $60.9 \%$ of respondents who teach, $80.0 \%$ of those responded that they cut back between "sometimes" and "all the time," with $20.0 \%$ who reported never or rarely cutting back. Similar results were obtained regarding the $62.4 \%$ of respondents who mentor, $80.1 \%$ of whom reported cutting back sometimes or more frequently, with a minority, $19.9 \%$, saying that they never or rarely cut back. Of the $57.9 \%$ of respondents who perform and publish research, there was a sharper decrease, with only $12.2 \%$ never or rarely cutting back, compared with $87.8 \%$ who did. Regarding the $87.8 \%$ of respondents who would participate in practice-building activities, $22.4 \%$ never or rarely cut back, compared with $77.6 \%$ who did. Of the $69.6 \%$ of respondents who voluntarily serve in radiology and academic societies, $21.8 \%$ of respondents never or rarely cut back on their service compared with $78.2 \%$ who did. The $95.6 \%$ of respondents who participate in Continuing Medical Education activities were most resistant to cut back, with $38.0 \%$ of respondents never or rarely cutting back compared with $62.0 \%$ who did. Of the $97.2 \%$ of respondents who read journals, $20.7 \%$ never or rarely cut back, compared with the $79.3 \%$ who did. Most interesting, only $97.2 \%$ of respondents reported spending time away from work, and of those, $21.8 \%$ never or rarely cut back on nonwork time, compared with $78.2 \%$ who did.

\section{Burnout Indices}

In answer to 4 commonly considered parameters of burnout or burning out workers, more than half of the respondents said that they had experienced increases in fatigue, difficulty relaxing after work, and diminished enthusiasm 
or effectiveness at work. On the fourth question regarding anxiety and depression, slightly less than half reported an increase. When asked if their practice administrators had made changes to help balance clinical and nonclinical work, only about 1 in 7 (14.2\%) said yes. More than half the respondents said that they considered retiring earlier than originally planned $(51.8 \%)$ and $38.9 \%$ have considered changing careers.

Statistically significant differences were found for several measures divided by experience. Neuroradiologists with $<20$ years of experience were more likely to have difficulty relaxing after work (65.1\%) versus those with $\geq 20$ years of experience $(50.6 \%, P=$ $.003)$. Neuroradiologists with $<20$ years of experience were more likely to consider retiring earlier than initially intended $(57.9 \%)$ versus those with $\geq 20$ years of experience $(42.4 \%, P=.002)$. Neuroradiologists with $<20$ years of experience were more likely to consider changing careers $(46.0 \%)$ versus those with $\geq 20$ years of experience $(28.0 \%, P<.001)$.

\section{DISCUSSION}

This article reports the results of the first survey of practicing members of the ASNR of their current work, their perceptions of changes in their clinical work, changes in their nonclinical work, their perceptions of their trainees, and 4 commonly used measures of burnout. Radiologists are among the most educated and highly trained professionals in the United States, requiring a minimum of 13 years of education after high school. Neuroradiologists require an additional year (or more) of fellowship training. Staying current requires a strong commitment not only to their work but also to maintaining certification through a combination of Continuing Medical Education and performing service and quality projects. Neuroradiologists thus represent not only a major personal commitment but also a substantial societal investment to create knowledge professionals.

The 21 st century has been a time of rapid change in medicine in the United States. Implementation of cost reductions and the shift from volume- to value-based reimbursement have had a strong impact on how radiologists practice. Private practice physicians in many parts of the United States have seen reductions in their autonomy, and others have shifted to employed practice (either voluntary or not); both of these trends have additional impact on the way radiologists practice.

This survey was implemented to begin a periodic process of understanding how neuroradiologists in the United States practice and how they view the quality of their work and its impact. This understanding is important for several reasons.

\section{Sustainability}

First, these results suggest crowding out of important nonclinical tasks that academic and private practice radiologists need to do to sustain their careers and their groups/departments. In 2000, Eschelman et $\mathrm{al}^{9}$ reported an inverse relationship between clinical productivity and academic productivity. If clinical demands crowd out academic work and practice building, then the academic mission will be compromised and the ability of radiologists to build and maintain their practices will be challenged. An important report from a leading academic neuroradiology practice showed that approximately one-fifth of productivity was non-RVU-generating. ${ }^{10}$

Second, the sustainability of the radiology enterprise depends on intergenerational work and cooperation. If clinical demands crowd out time for effective teaching, mentoring, and academic project work, the profession itself is at risk. While correlation is not proof of causation, 93.5\% (243/260) of our respondents who teach reported a degree of cutting back on teaching, with almost half reporting cutting back frequently or always, $48.1 \%$ (125/260). Mentoring activities showed similar degrees of reported reductions. These are professionals acknowledging that they are not doing important tasks for the future of the profession.

The perceptions of neuroradiologists that there has been a decline in the quality of trainees is concerning for the future of the profession and should be investigated further because it could be due to many factors, including the following: generational misunderstandings, burnout in the current teaching cadre leading to overly harsh evaluations, declining educational standards at the medical school level, and/or a decline in the quality of trainees self-selecting into a radiology career.

\section{Potential for Future Workforce Shortage}

Although considering early retirement or career change does not necessarily equal intention, it raises the possibility of a shrinking workforce, compounded by recent trends in the general diagnostic radiology National Resident Matching Program.

The historical data from 2004 to $2015,{ }^{11-15}$ years for which information was available at the time this manuscript was written, show a divergence beginning in 2011 in the number of offered training positions from the number of filled positions (Fig 6) in diagnostic radiology residencies. Regarding neuroradiology fellowship positions, there was a milder and delayed divergence between offered positions and filled positions beginning in 2014 (Fig 7), which may be expected, given that fellowship applications occur 4 years after diagnostic residency applications in the third year of residency.

Data from the 2016 National Resident Matching Program, ${ }^{16,17}$ however, show an increase in the fill percentage of both diagnostic radiology programs $(96.4 \%)$ and neuroradiology fellowships $(80.5 \%)$ compared with the 2015 year $(86.3 \%$ and $74.5 \%$, respectively), a deviation from the trend of the previous 5 years.

Depending on whether the 2016 data are an anomaly compared with the trailing trend of the past half-decade versus an important inflection point for reversal of the trend, the implication for the availability of future trainees to replace retiring neuroradiologists is great. If the 2016 data are an anomaly, radiology and thus neuroradiology may find itself unable to replace both radiologists who retire as planned when first beginning their careers and any who may retire early or change careers due to burnout. That situation could create a negative cycle, exacerbating the problem. On the other hand, if the 2016 data represent an inflection point, the possibility of a future workforce shortage may be less. More future data points will be needed to evaluate these possibilities.

AJNR Am J Neuroradiol 38:1284-91 Jul 2017 www.ajnr.org 


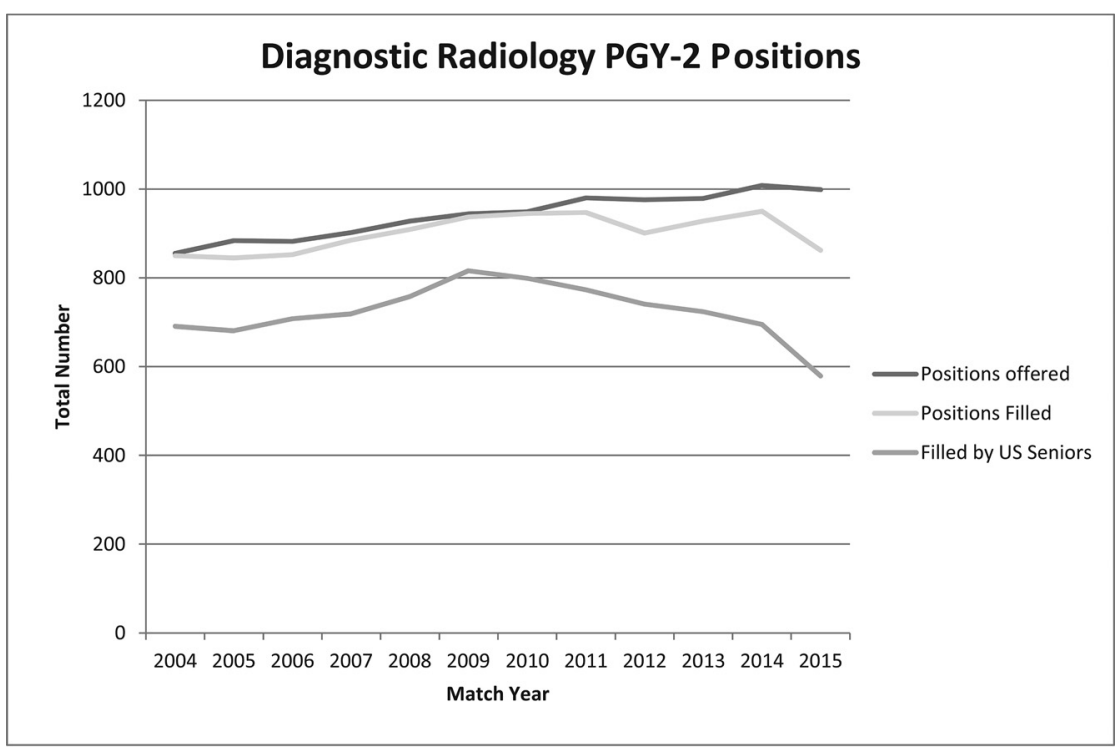

FIG 6. Positions offered in the diagnostic radiology match of the National Resident Matching Program compared with number of positions filled in total and by seniors in the United States. Beginning in 2011, there is a divergence between number of offered positions and filled positions, with a sharper drop in the number of positions filled by seniors in the United States. PGY-2 indicates postgraduate year 2, or first year of a typical radiology residency.

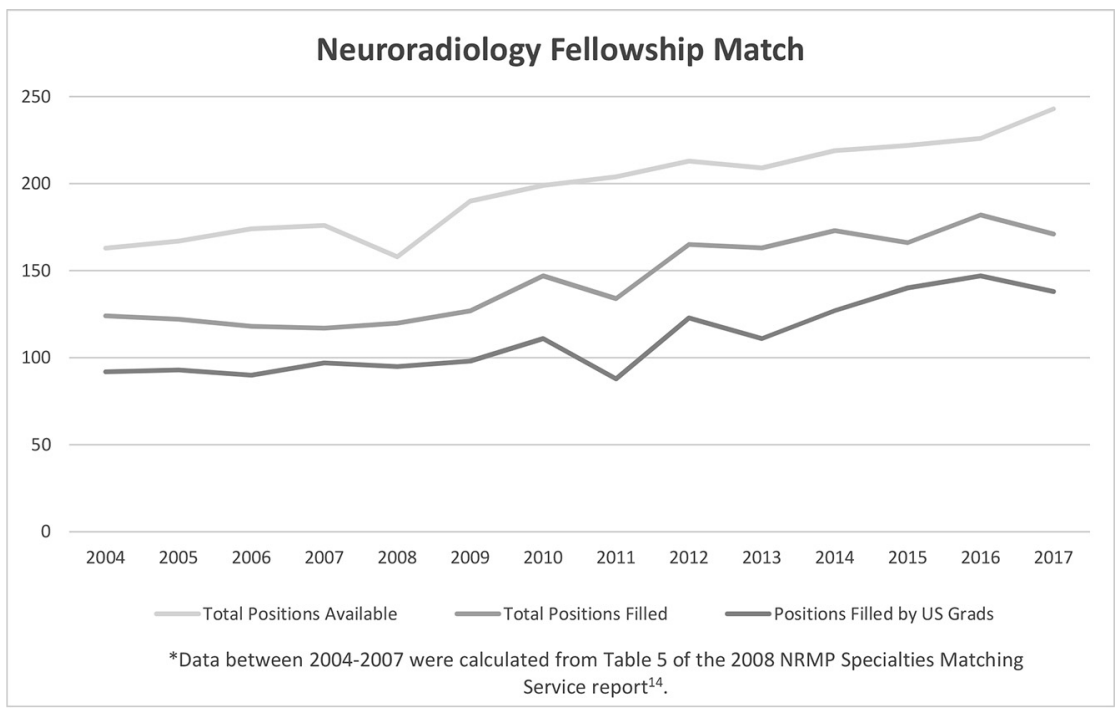

FIG 7. Positions offered in the neuroradiology fellowship match of the National Resident Matching Program compared with number of positions filled in total and by graduates in the United States. The total number of filled positions in 2014 and 2015 appears to have leveled off, despite the larger number of offered positions compared with previous years.

\section{Burnout}

Burnout is a serious threat for this cadre of neuroradiologists. A study of physician happiness comparing specialties reported in 2015 that radiologists were the least happy of 27 types of specialists on a Likert scale. ${ }^{18}$ Another report with different methodology also showed radiologists in the lower half of a large group of major medical specialties in reported happiness at work. ${ }^{19}$ Burnout is often misunderstood by physicians and administrators. Delay in diagnosis can occur if there is an ignorance of early warning signs. The late indicators include poor work performance, visible anger-yelling, throwing things, verbal abuse, and so forth as well as inappropriate be- havior and medical malpractice. By the time these indicators are manifest, serious personal and professional impairment has already occurred.

Workplace unhappiness extends far beyond the employment setting. It affects relationships, including divorce, and can lead to substance abuse and sleep and eating disorders and neglect of hygiene and health. In a 2015 report, burnout in physicians correlated with the following: a lower rate of volunteerism, worse health, lower exercise, greater likelihood of obesity, less savings, and more likely never being married and being alone. ${ }^{20}$ Burnout is also linked to a higher rate of depression; not surprisingly perhaps, the suicide rate among physicians in the United States is higher than that in the general population and is worse for female physicians. ${ }^{21}$

Earlier warning signs of burnout include what have been called the " 3 D's": disengagement, disinterest, and disconnection. Also, watch for loss of communication, truancy, heightened cynicism, and aggression.

A second problem with accurate diagnosis and treatment of burnout is that burnout is often misunderstood as a character flaw. For example, one may ask why one radiologist cannot work as hard or as long as another? There must be something wrong and so forth. Like posttraumatic stress disorder, burnout can happen to the best of neuroradiologists, despite good character, good training, and so forth. The focus on the individual can also distract leaders and administrators from addressing environmental issues. While some may burn out sooner than others, if a group or department is seeing advanced burnout in one member, that should be a warning to others as well.

The same article that noted the level of unhappiness in radiologists compared with other specialties also noted that $10 \%$ of radiologists in the United States were severely burned out. ${ }^{18}$ In a different article, $49 \%$ of radiologists reported at least some burnout. ${ }^{18,22}$ Radiology was not the specialty with highest rate of burnout (urology and critical care were the worst), but it was in the top half of specialties examined and reported. ${ }^{18}$

Burnout is increasing in the United States. A report in the Mayo Clinic Proceedings from 2011 to 2014 showed that the percentage of physicians reporting at least 1 symptom of burnout increased from $45.5 \%$ to $54.4 \%$, while satisfaction with 
work-life balance fell from $48.5 \%$ to $40.9 \% .^{22}$ These changes in the medical profession should be considered serious, particularly given that the general population of the United States showed only minimal changes in the same time period. ${ }^{22}$ Similarly, another report showed increasing rates of physician burnout from 2013 to 2016, with consistently greater rates in women than men. ${ }^{19}$

A recent report from an American College of Radiology Commission focusing on the issue of burnout suggested several remedies for preventing burnout. The highest impact recommendation was to provide adequate staffing. ${ }^{23}$

\section{Limitations}

This survey has several limitations. It was voluntary, and it is possible that responders are different from the broader neuroradiology community. This is a survey and not an audit of radiologists' work. It is thus open to response and recall biases.

Other authors have noted bias issues in how radiologists and their groups report workload. ${ }^{2,24}$ The survey may underestimate changes in workload and difficulty because it does not distinguish between neuroradiologists who work full-time versus neuroradiologists who work part-time or have recently cut back their clinical time.

The number of studies interpreted on-call is likely a gross overexaggeration because it mixes those who take full-subspecialty neuroradiology calls (likely nearly entirely CT and MR imaging) with more general calls (which likely include other modalities beyond CT and MR imaging) and is further confounded by the lack of detail captured in the survey to give those responses context. The survey did not distinguish between preliminary oncall interpretations versus final interpretations or the number of total on-call hours spent interpreting studies, among other confounds.

\section{CONCLUSIONS}

This is the first survey in a planned series of surveys of the American Society of Neuroradiology to track changes in radiologists' work, their work environment, and the effects on the quality of their profession and personal lives. Increasing clinical work demands have coincided with destructive effects in the work environment and the ability and desire of radiologists to perform academic or practice-building duties, with a substantial incidence of burnout symptoms in neuroradiologists in the United States. While this survey does not prove causation, the trends and the correlations should be concerning to radiologists, their groups/departments, and their leaders and warrant further monitoring.

\section{REFERENCES}

1. McDonald RJ, Schwartz KM, Eckel LJ, et al. The effects of changes in utilization and technological advancements of cross-sectional imaging on radiologist workload. Acad Radiol 2015;22:1191-98 CrossRef Medline

2. Bhargavan M, Kaye AH, Forman HP, et al. Workload of radiologists in United States in 2006-2007 and trends since 1991-1992. Radiology 2009;252:458-67 CrossRef Medline

3. Ridley EL. Workload analysis helps enable subspecialized reading.
AuntMinnie. February 10, 2014. http://www.auntminnie.com/index. aspx $? \sec =\sup \& \operatorname{sub}=$ pac\&pag $=$ dis $\& I t e m I D=106458$. Accessed October 29, 2016

4. Lu Y, Arenson RL. The academic radiologist's clinical productivity: an update. Acad Radiol 2005;12:1211-23 CrossRef Medline

5. Lu Y, Zhao S, Chu PW, et al. An update survey of academic radiologists' clinical productivity. J Am Coll Radiol 2008;5:817-26 CrossRef Medline

6. Hankiss J. Burn-out...the big danger? [in Hungarian]. Orv Hetil 2015;156:1188 CrossRef Medline

7. Du H, Qin L, Jia H, et al. Relationship between job burnout and cognitive function and influencing factors of job burn out among medical staff [in Chinese]. Zhonghua Lao Dong Wei Sheng Zhi Ye Bing Za Zhi 2015;33:676-78 Medline

8. Frutos-Llanes R, Jiménez-Blanco S, Blanco-Montagut LE. Burnout syndrome in general practitioners of Avila [in Spanish]. Semergen 2014;40:357-65 CrossRef Medline

9. Eschelman DJ, Sullivan KL, Parker L, et al. The relationship of clinical and academic productivity in a university hospital radiology department. AJR Am J Roentgenol 2000;174:27-31 CrossRef Medline

10. Wintermark $M$, Zeineh $M$, Zaharchuk G, et al. Non-relative value unit-generating activities represent one-fifth of academic neuroradiologist productivity. AJNR Am J Neuroradiol 2016;37:1206-08 CrossRef Medline

11. National Resident Matching Program. Results and Data: 2005 Main Residency Match. Washington, DC: National Resident Matching Program; 2005

12. National Resident Matching Program. Results and Data: 2010 Main Residency Match. Washington, DC: National Resident Matching Program; 2010

13. National Resident Matching Program. Results and Data: 2015 Main Residency Match. Washington, DC: National Resident Matching Program; 2015

14. National Resident Matching Program. Results and Data: Specialties Matching Service 2008 Appointment Year. Washington, DC: National Resident Matching Program; 2008

15. National Resident Matching Program. Results and Data: Specialties Matching Service 2010 Appointment Year. Washington, DC: National Resident Matching Program; 2010

16. National Resident Matching Program. Results and Data: 2016 Main Residency Match. Washington, DC: National Resident Matching Program; 2016

17. National Resident Matching Program. Results and Data: Specialties Matching Service 2016 Appointment Year. Washington, DC: National Resident Matching Program; 2016

18. Peckham C. Physician burnout: it just keeps getting worse. http:// www.medscape.com/viewarticle/838437_2. Accessed May 6, 2016

19. Peckham C. Medscape lifestyle report 2016: bias and burnout. http:// www.medscape.com/features/slideshow/lifestyle/2016/public/overview. Accessed May 9, 2016

20. Peckham C. Medscape physician lifestyle report 2015. http:// www.medscape.com/features/slideshow/lifestyle/2015/public/overview. Accessed January 2, 2017

21. Andrew LB. Physician suicide. Medscape. Updated October 3, 2016. http://emedicine.medscape.com/article/806779-overview. Accessed May 11, 2016

22. Shanafelt TD, Hasan O, Dyrbye LN, et al. Changes in burnout and satisfaction with work-life balance in physicians and the general US working population between 2011 and 2014. Mayo Clin Proc 2015;90: 1600-13 CrossRef Medline

23. Harolds JA, Parikh JR, Bluth EI, et al. Burnout of radiologists: frequency, risk factors, and remedies-a report of the American College of Radiology Commission on Human Resources. J Am Coll Radiol 2016;13:411-16 CrossRef Medline

24. Sunshine JH, Burkhardt JH. Radiology groups' workload in relative value units and factors affecting it. Radiology 2000;214:815-22 CrossRef Medline 